\title{
Design for All Approach with the Aim to Support Autonomous Living for Elderly People in Ordinary Residences - An Implementation Strategy
}

\author{
Claes Tjäder \\ The Swedish Institute of Assistive Technology (SIAT) \\ Box 510, SE - 16215 Vällingby, Sweden \\ claes.tjader@hi.se
}

\begin{abstract}
Most elderly want to remain in their ordinary home. There are products and services available which make it possible to support an autonomous living with a high quality of life. To finds ways how to implement DfA supportive technology in co-operation with housing enterprises is dealt with in this paper. Methods used at some workshops to single out measures from different perspectives are described.
\end{abstract}

Keywords: Elderly, autonomous living, implementation strategy, DfA technology support, real estate and/or housing enterprises.

\section{Introduction}

Already today but even more tomorrow the ordinary residence will be a place where home care and health care support is given. Supportive Design for All technology can be one ingredient in a coherent strategy to realise the desire for most elderly to remain in an ordinary residence.

This paper deals with the challenge on how to introduce the technology support into the flats and jointly used facilities in block of flats.

\section{Demographic Development}

With a growing proportion of the population over the age of retirement, and a predicted rise in the proportion of people with disabilities, the cost of social and institutional care will grow. EU-citizens nowadays live 8 years longer than they did 30 years ago. Improved health and life conditions result from measures taken at a European, national and regional level. A woman born in EU today will reach an average lifetime which is 81,4 and a man 75,3 and it will increase.

To be able to remain for a longer time in the ordinary resident is important from several perspectives. The most important one is obvious, most elderly want to remain in their ingrained environment as long as possible due to the fact that the daily life functions. Other aspects are the lack of good alternatives to the existing residences. The number of elderly is increasing every year, in some years the number of elderly 
will exceed the level of today essentially as a result of the great numbers of children born during the $1940-1959$.

This paper deals with a possible contribution to enhancing the quality of life and reducing the social and economic costs, and developing a strategy for supporting an ageing population in Europe.

Technology can be an ingredient in a strategy supporting an ageing population in Europe with the aim to enhance the quality of life.

\section{Technology Is There}

In a national 3 year project (Technology support at Home) SIAT has been working together with user organisations, municipalities and housing enterprises in developing and testing supportive technology for elderly with cognitive impairments. These target groups have high demands on usability. As more people become elderly more people will face cognitive difficulties, at first, and cognitive impairments later on. By working together with users with cognitive difficulties and impairments when testing and developing products, services and methods, only those with accessible design will meet the user requirements. On the other hand, those products, services and methods that meet the requirements originating from users with cognitive difficulties most likely will also be easy to use by other user groups. This could then be a way forward when developing supportive technology initially designed for some fragile groups into mainstream products and services.

The result from the practical 3 year project showed that of 60 IT based technical support devices/installations, 4 of 5 had a positive effect. The devices concerned smart home technology and cognitive support. They built on routines the users had. The evaluations were done in relation to increased autonomy and ability by occupational therapists.

\section{Who Is the Customer?}

Some products are now being launched on the market. Reminder systems for example integrated in ordinary residences using the same IT-infrastructure as systems for energy efficiency and individual measuring of water or energy consumption in block of flats is of course beneficial for real estate owners. But also families with children could enhance their quality in life with the DfA product - "go out button" which give tenants a reminder, when leaving the residence, in case they have forgotten to switch off some electrical appliances, the water or not locked the door properly. This kind of system can now be seen in some new ordinary block of flats. At the same time it could be stated that the introduction takes time. This is the fact in many countries.

Findings in research in Sweden about elderly indicate that early introduction of technical support is vital for the user. It is also demonstrated that introduction of technical support should be seen in conjunction with other measures such as support from relatives, house adaptations or home care from the municipality.

There are no systems available which have integrated all the technologies and designed services around them even though technology has been available for many years. 
Could the technical support be part of the public undertaking versus elderly or is it a responsibility for the elderly themselves? From a company perspective it is paramount to clarify that kind of question.

We can now see some installations of supportive technology in line with DfA concept already made in my country by some real estate companies as a part of a comfort package included in the monthly rent.

\section{Implementation Strategy}

In the following a process will be described. The aim with the exercise is to come forward with some kind of "recommendation" or "good advice" to housing enterprises and/or real estate owners. The ambition is to achieve some concrete results during 2009.

\subsection{Aim with an Implementation Strategy}

The following aims have been formulated:

- to make it possible for as many elderly as possible to live an autonomous life with high quality in an ordinary residence they have chosen themselves.

- to establish a co-operation between several actors - public and private - targeting a "win-win-situation".

- to introduce technical support in a context together with other measures with the aim to increase physical and cognitive accessibility and social measures such as home care support.

- to raise awareness of products and services available on the market and clarify burden sharing between society and the elderly themselves.

\subsection{Supportive Technology for All - A Process Initiation}

Within SIAT and in co-operation with external actors a process has been initiated to concretize the implementation strategy with the aim to facilitate introduction of products and services in block of flats. The target group for the process is housing enterprises and real estate owners that already today have demonstrated an interest. In our case it means municipality owned and cooperatively owned block of flats. Basically the process is built on the insight that the gap between social sector and the real estate industry needs to be narrowed.

Recently SIAT was involved in a project aiming to define the requirements of a future network for broadband not only in new block of flats but also for block of flats when there is need to make a major maintenance investment such as replacement of water and sewage systems. The initiator to that project was the Federation for municipality owned enterprises that wanted to take the future social and health care services into account when planning for future IT infrastructure in ordinary residents. Recently the result of this specific project has been used in both a planning process for a new residential area and in a process where a big municipality owned company in the Stockholm area is uses the result when planning major maintenance investments in 
residents for elderly. This is an example that could help creating more business cases in the future.

\subsection{Driving Forces and Method Chosen - Where to Start?}

The needs are with the end users, that is why the products and services must have this as the starting point. Just as crucial is the fact that the companies developing products and services must have in mind how the product or service is to be marketed or who is to pay.

A large and strong interest to make the product and service commercially viable is extremely important. Up till now there has been a huge difference between consumer products and services on one hand and assistive products on the other when it comes to marketing and driving forces. As the market conditions vary the companies acting on the procured market and the company on the ordinary consumer market uses different strategies.

Within the framework of workshops, which also involved representatives from private sector, the strategy for implementation was outlined.

It was stated in the beginning that it would be useful to limit the scope to some real estate owners. As a result of that consideration focus in the workshops was on municipality owned companies and co-operatively owned (tenant owners). The municipality owned companies do have a double responsibility. They have to make sure that the municipality owned block of flats constitute a good and competitive alternative to present and new tenants. Municipalites do also have a responsibility via the social care service versus elderly and the their housing conditions and persons with disabilities.

As a result of the different roles the municipalities hold SIAT draw the conclusion that it would be natural to address the municipality owned enterprises when starting the work with a possible implementation strategy.

Some co-operatively owned ( tenant owners) block of flats also have demonstrated a genuine interest in technology support of DfA character. Some also have clearly expressed an interest to take measures to support tenant owners to be able to remain in their ordinary residence as long as possible with a high quality of life. To investigate and to get a better picture of what these co-operatively owned block of flats already have done was a natural activity. It was seen as a part of a strategy that a co-operation with these organisations could be very fruitful. Especially when it comes to dissemination of a future strategy these co-operatively owned block of flats, with own experiences, could be very useful partners as we want to reach out with a message on the usage of DfA supportive technology.

\subsection{What Was the Purpose with the Workshop Series?}

The workshop series included hands-on activities. It was a combination of presentations, individual and group activities such as:

1. Listing of proposals and prioritization of the products and services which were seen to be important to housing enterprises when they do decide on major maintenance investments or initiate new production.

2. Create understanding for what is needed to make it possible for good products and services to come into use. 
3. Initiate development of strategies which leads to the result that real estate owners and /or housing enterprises invest in technology support which facilitate for elderly to remain in their ordinary residences with a high quality of life.

The result from the opening workshop is shown in figure 1 .

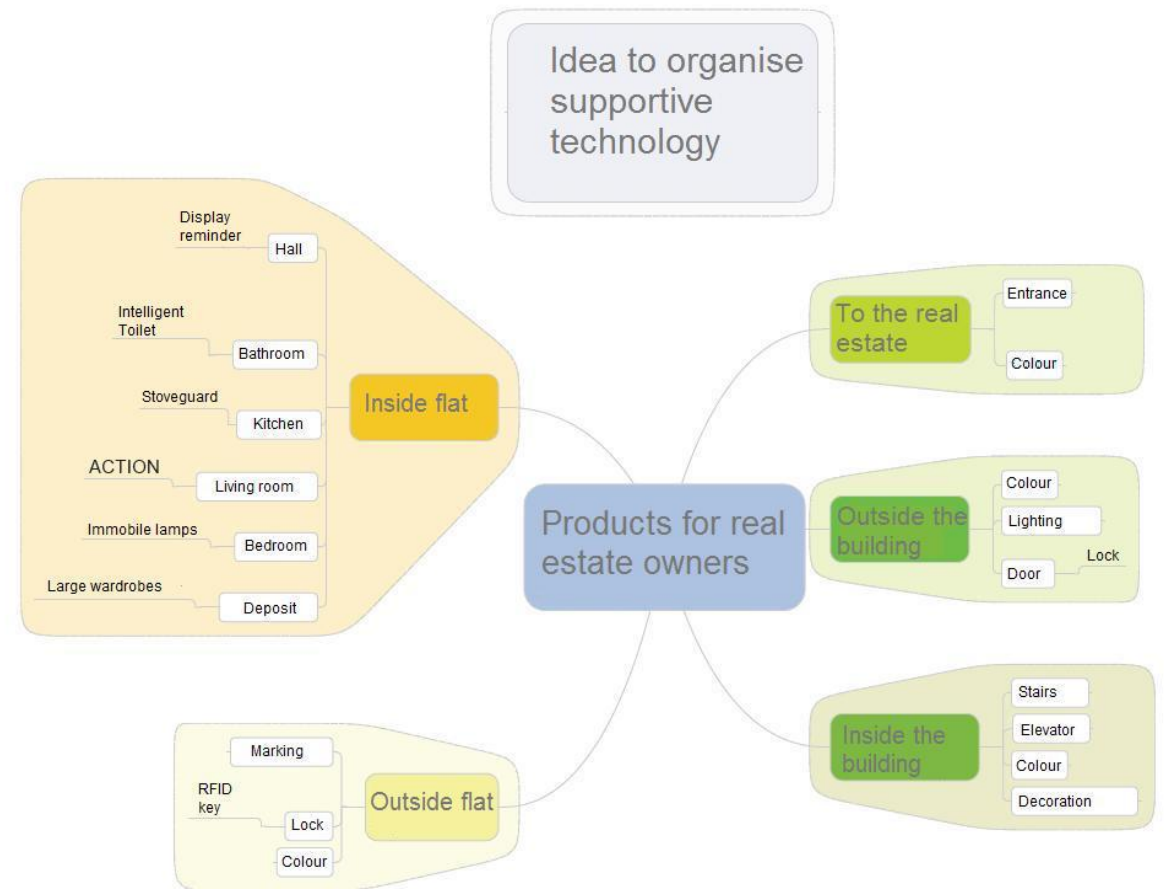

Fig. 1. Results from the opening Workshop

At the end of a following workshop we discussed possible criteria for selecting certain products and services.

The main purpose with the selected products and services were to enhance the conditions for elderly and people with impairments when it comes to housing and living conditions.

That does not exclude that other groups of users such as relatives or personnel could benefit from the products and services chosen.

During the first two workshops the main task was to select products and services, some examples are given in figure 1.

At the end of workshop 2 we discussed the criteria for selecting certain products and services.

It was also questioned whether the criteria should be somewhat different.

Perhaps a better way would be to scrutinize how the products and services should be marketed to be successful versus the real estate owners. 
It was mentioned that the word assistive technology to some people is stigmatizing. Then it would be better to use the word technology support as that expression is more neutral. The idea was to focus on how to make the presentation.

Another conclusion was to concentrate on functionalities and to describe the usefulness for most tenants from different perspectives rather than on the special needs that elderly and people with impairments have.

One example was the usefulness that a easy interface for a booking system in common wash house.

Cognitive symbols easily recognizable and understandable are other examples of "products" that are easy to explain from a usefulness perspective.

The aim with the workshop 1 and 2 was to chose and create methods and descriptions in order to augment the interest among real estate owners for:

- The supply of good products to facilitate ordinary daily activities at home

- The value of technology support for the tenants

- The value for real estate owners for the selected products and services.

- The installation of the "recommended" products and services.

\subsection{Selection Criteria}

The next phase included a method to describe efforts and effects. The products and services were first positioned individually by every workshop participant in the diagrams showed in figure 2 and 3 and later on collectively discussed during the workshop.

A product which is placed in the top left is presumably less interesting compared to a product which is placed in the right hand corner along the x-axle, see figure 2 . In figure 3 the products were introduced in relation to the overall goal to most elderly

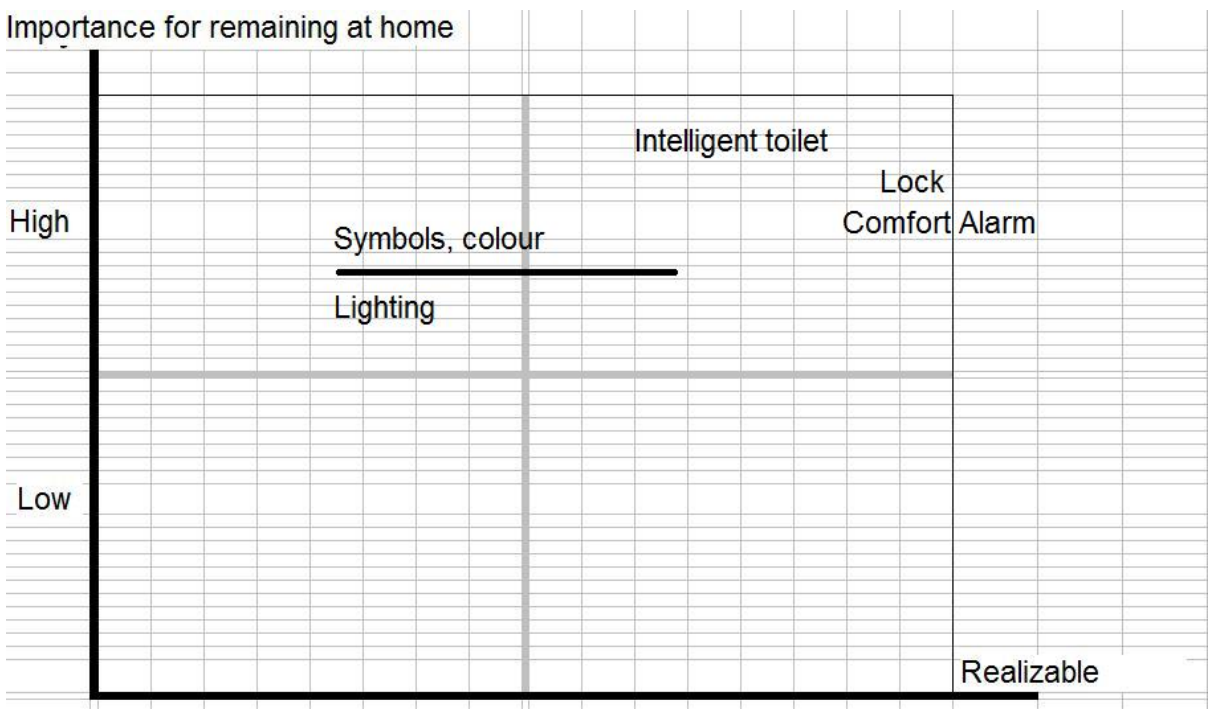

Fig. 2. Importance for remaining at home 


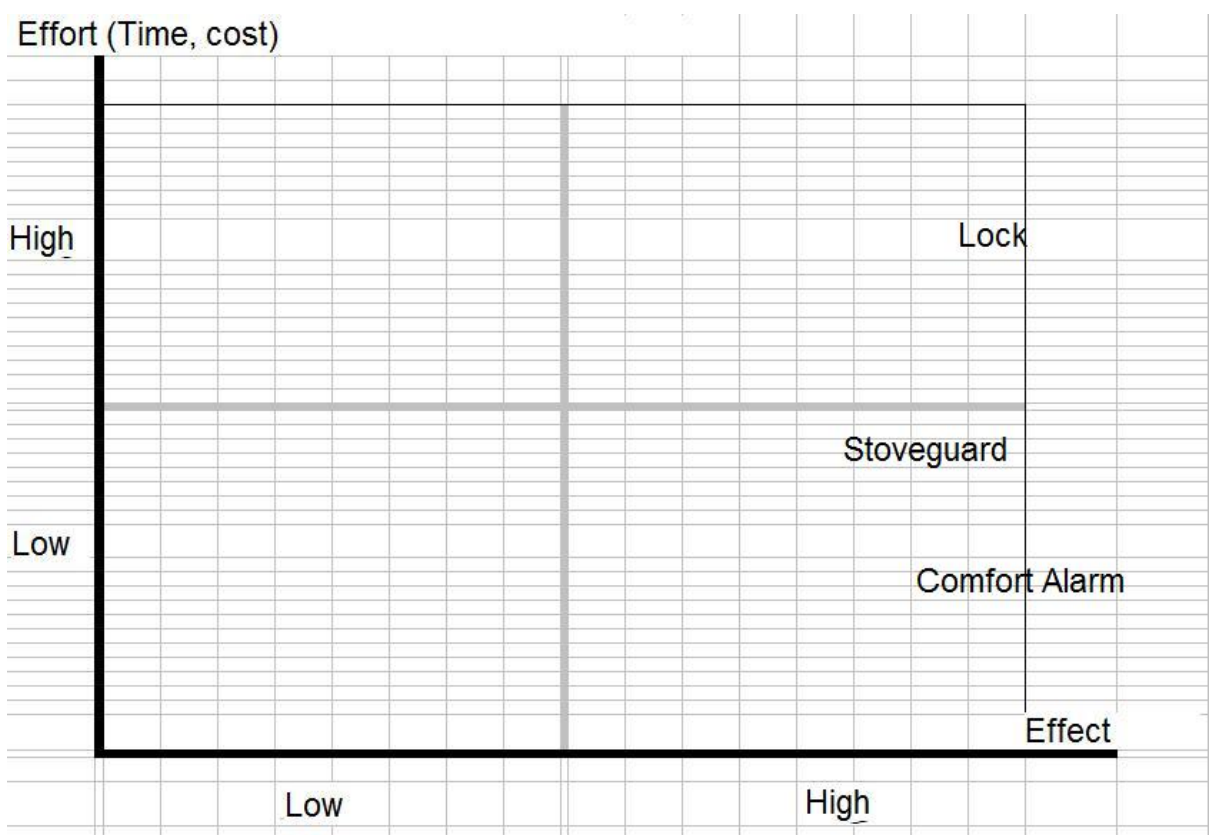

Fig. 3. Effort for remaining at home, versus time and cost

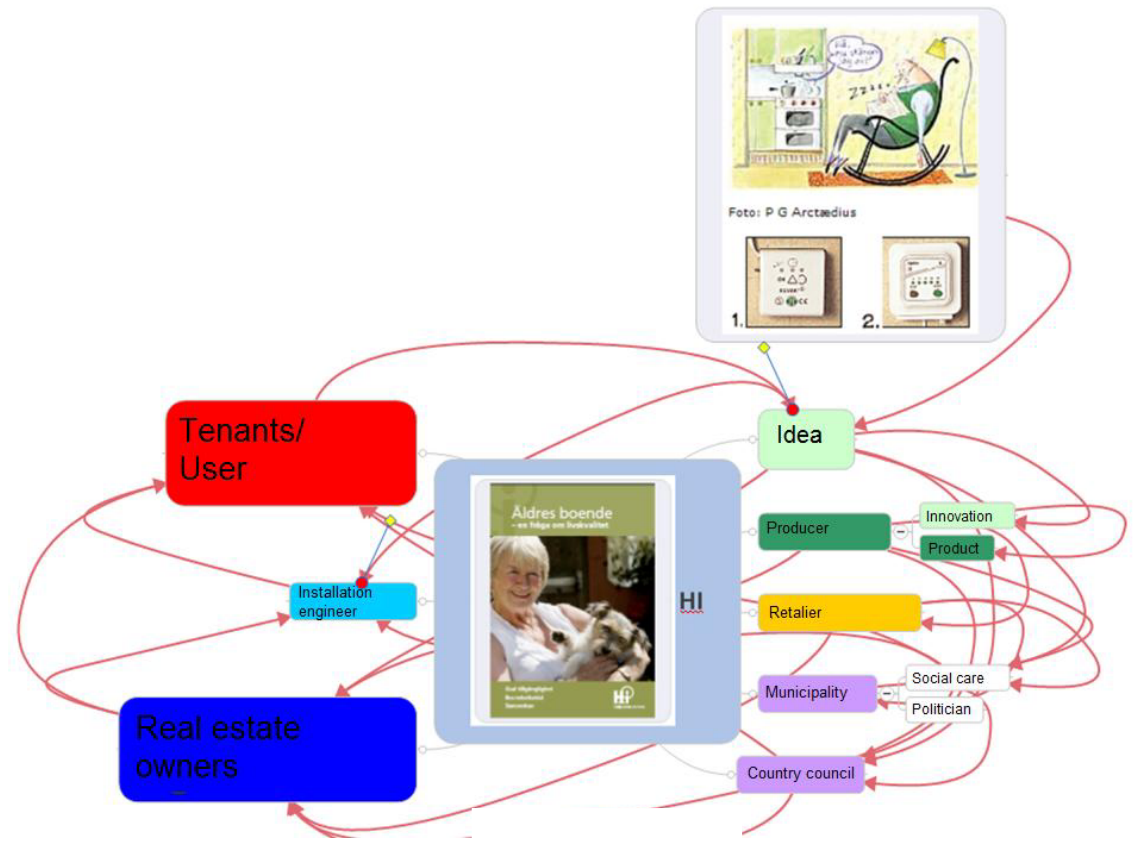

Fig. 4. Complexity of the approach followed 
namely to what extent the product or service can contribute to remain at home in the ordinary residence. At the HCI Conference 2009 I will in my presentation share examples from workshops of products and services positioned into these figures. As examples I have inserted some products in the figures.

Activities needed to go all the way from the producer to the end user is built on an interchange of contacts between several organizations. If you not are aware of what groups that needs to be satisfied you might end up in a result where good products remains as pilot projects. To meet the economic conditions and to understand complexity is crucial.

In figure 4 an effort has been made to try to illustrate the complexity, when you take several actors into account.

\subsection{Obstacles and the Way Forward}

At one workshop we tried to identify obstacles which make it difficult to introduce the supportive technology. The solution we believe lies in finding the argument which neutralises the problems and if possible demonstrates new opportunities instead.

During this exercise we used the method with the "six thinking hats", a model developed by the Edward de Bono. He claims that in a changeable world you have to focus on what it is going to be instead of what it is and thinking is something that can developed. "Six thinking hats" is used worldwide from preschool to global companies.

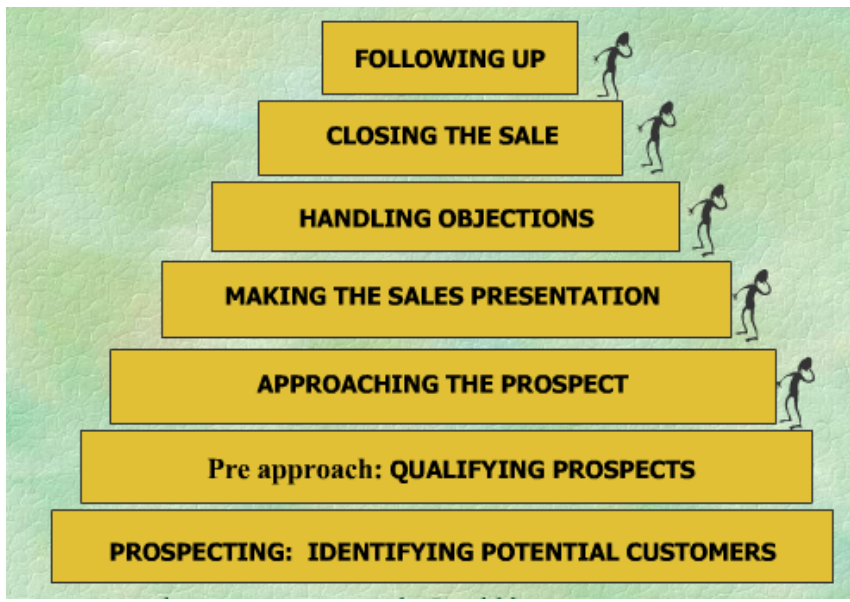

Fig. 5. The "Hat model"

The purpose with the "hat model" is to get a better understanding of the structure of thinking. As an example by starting with analyzing possible arguments against a certain product (black hat) we elaborated some problematic areas. This was followed by exercises where we used for example the "green hat" (corresponds to creativity and new ideas) where the group came up with proposals, new arguments and solutions.

In the links between the actors there is a need for information and selling activities which is described in figure 5. This means in practical life that it is not always easy to 
release different products from a variety of suppliers. One supplier/distributer with a well-known brand and well functioning channels has a much easier way to reach out to the market than many small suppliers with a weak brand. It is of vital importance to take this into account if you want to work effectively and result-oriented.

\subsection{How to Speed Up the Process?}

The 3 year project - Technology support at Home - mentioned in the beginning of the paper still is now being followed-up by several measures. The technology is there but there is no comprehensive "package" to deliver.

A key issue is that real estate owners and housing enterprises have to be involved as users of the products and services available already today.

Real estate owners lack good examples of what could be done with products and services to make it possible for elderly to remain in the ordinary residences.

Activities in my country and elsewhere can contribute to speed up implementation of supportive DfA technology.

Our ambitions in Sweden are to present Guide lines and requirements, when it comes to physical accessibility and technical support, for actors involved in planning and procuring housing for elderly. The process described above aims to complement these Guide lines with some sort of "Recommendations" on what kind of products and services available on the market that fulfils the DfA requirements. At the Conference I will be able to elaborate on some results from the process described above. 